\title{
Augmented Reality in Offline Retail: Integrating the Affordance and Means- End Chain Perspectives
}

\author{
Camen Teh \\ University of Nottingham \\ Ningbo China \\ camen.teh@nottingham.e \\ du.cn
}

\author{
Chee Wei Phang \\ University of Nottingham \\ Ningbo China \\ cheewei.phang@nottingh \\ am.edu.cn
}

\author{
Alain Yee Loong Chong \\ University of Nottingham \\ Ningbo China \\ alain.chong@nottingham. \\ edu.cn
}

\author{
Zixiu Guo \\ UNSW Sydney \\ z.guo@unsw.edu.au
}

\begin{abstract}
This paper presents an integrated approach that combines both the affordance and means-end chain (MEC) perspectives to examine the cognitive structure of offline retail consumers in relation to the material properties of Augmented Reality (AR) technology. Drawing from both perspectives, we propose that while an information technology (IT) artefact gives rise to affordances through its interactions with users' goals, personal values play a role in the emergence of affordances as well. We present our preliminary study whereby we conducted 15 laddering interviews to investigate how consumers use AR, the benefits that consumers seek to obtain when using AR in offline retail and why they seek to pursue them. Our findings suggest that the AR affordances that emerged in relation to consumers' goals enable consumers to achieve both utilitarian and hedonic values. Further, we identified and discussed AR-related boundaries stemming from user and AR capacity limitations. Based on our exploratory findings and proposed integrated framework, we conclude this paper with suggestions on potential future research directions.
\end{abstract}

\section{Introduction}

Augmented reality (AR) is a growing subject of interest for practitioners and scholars alike, owing to the technology's unique properties that can offer unprecedented potential. In a world where gamers now physically chase after virtual creatures in real-life environments such as in the AR game, Pokémon Go, one can wonder about what other possibilities AR can offer. These possibilities seem optimistic, as the AR market is predicted to increase to more than 198 billion USD by 2025 from its size of 3.5 USD in 2017 [1].

While AR has made waves in the gaming industry, prior reports have also indicated the potentials of AR in the retail industry, specifically through AR applications such as virtual try-ons and interactive product information presentation [2,3]. On the other hand, scholarly literature on AR in retail has mostly focused on its application in the online setting, among which examined the adoption of AR in online retail [4], media characteristics of AR in e-commerce [5] and consumer behavior in relation to online AR use [6].

However, AR research in offline retail is sparse, and this is confirmed by a recent literature review [7]. We argue that offline retail remains to be an important touchpoint for consumers, and it is worth exploring what AR can offer consumers in their offline shopping. For instance, AR's ability to embed digital, virtual information into consumer's physical environment in three-dimension and in real-time, as defined by Azuma [8], is an unprecedented phenomenon that has the potential to solve consumer problems such as information asymmetry, where there is a pervasive knowledge gap between consumer and retailer about a product. AR's unique ability to provide vivid, enriched information that would typically be unavailable in brickand-mortar stores can enable and empower consumers to make informed purchase decisions. It is conceivable that the amplified information enabled by AR, combined with consumers' ability to physically interact with a product, makes AR-supported offline retail an ideal shopping setting for consumers to make their purchase - if not the most ideal, in comparison to online shopping and conventional offline shopping.

To the best of our knowledge, no systematic investigation has been conducted to explore the potentials that $\mathrm{AR}$ attributes can offer to users in offline retail, as well as why these are important to users. Ascertaining the unique AR attributes that are salient to users can help us unravel the black box of what is it about AR specifically that can enable users when shopping in brick-and-mortar stores. From a scholarly perspective, exploring the attributes that can lead to noteworthy outcomes can provide future researchers with potential research directions that are grounded from the uniqueness of AR technology. Against this backdrop, we present the findings of our qualitative study that explores the affordances of AR in offline retail, focusing on the interaction between goal-oriented 
users and material properties of AR. Specifically, we draw from both the perspectives of means-end chain (MEC) and affordance theory to answer the following research questions: (1) what are the AR attributes that can enable offline retail shoppers?; and (2) why do shoppers use AR?

We employed the laddering technique, a common method used in MEC studies, to collect and analyze our data from a sample of 15 participants. Based on our findings, we propose a framework that shows how goaloriented users interact with material properties of AR and the AR cognitive linkages that drive affordance actualization and use behavior. Our proposed model also takes into consideration potential boundary conditions of AR affordances that were revealed in our findings.

\section{Conceptual background}

For this study, we integrate the affordance and MEC theory to identify AR affordances. On its own, the affordance theory explains that IT affordances emerge through the interaction between goal-directed actors with an IT artefact [9]. However, by integrating the MEC theory, we are able to deconstruct this interaction to understand more clearly how and why affordances arise by zooming into the goal-orientation aspect of actors. We use the laddering method commonly associated with the MEC theory [10] to identify the abstract motivations behind users' interaction with material properties of the AR artefact. Drawing from the MEC theory [11], we view that users interact with technologies as a goal-directed action to satisfy underlying personal values. In other words, the actors' interaction with material properties of IT are essentially guided by their personal values. The focus of MEC theory on the linkages between technology attributes, the consequences these provide and the personal values fulfilled enables us to unearth AR user motivations, thereby allowing us to interpret AR affordances from a goal-directed lens. We explain both theories in more detail in the following sections.

\subsection{Affordance theory}

The affordance theory draws from ecological psychology, focusing on the interaction between an actor with the environment [9]. A key tenet of this theory is that "a goal-directed actor perceives objects in the environment in terms of how they can be used" [12] (p. 233). In other words, an object is perceived as what it can afford, and its potentials for meeting the actor's goals. According to Gibson [9], these potentials arise from both the properties of the actor and the object - thus, affordances are the potentials of the interaction between actor and object, rather than a set of attributes inherent to the object and separable from the actor [12].

The affordance theory has been used in information systems (IS) research, both in studies on the organizational level [13], as well as on the individual level [14]. Figure 1 shows the affordance theoretical framework that explicates the intertwining of the properties of the IT artefact and goal-directed actors, which gives rise to affordances. These affordances are then perceived by the actors and subsequently acted upon (actualization of the perceived potentials or affordances). This is essentially a goal-directed behavior, reflecting the actor's volition of taking action on the affordance, which consequently produces outcomes $[15,16]$.

We adopt the affordance theory for this study as an overarching framework to identify AR use mechanisms, which can later be further unraveled to build ARspecific theories that explain the patterns found [17]. As Bygstad et al. [17] highlight, the affordance approach can be viewed as a tool to identify structural components of IT-related mechanisms and the interrelationships of these components which produce an outcome.

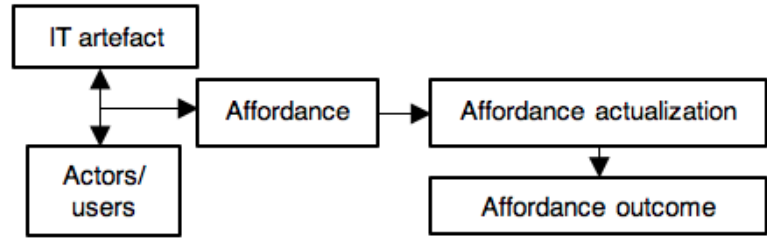

Figure 1. Affordance theoretical framework
adapted from Pozzi et al. [15]

\subsection{Means-end chain (MEC) theory}

The MEC theory is developed by Gutman [11] with the objective of understanding consumer decisionmaking process. This theory argues that products are collections of attributes, whereas consumers are holders of values [11, 18]. Attributes of products lead to consequences (or benefits) derived from using the products, which in turn gratify the consumer's values. Using the MEC approach, the linkages between attributes, consequences and values are mapped to identify the attributes that make products personally relevant to the consumers, in addition to ascertaining the values that are important to consumers [19].

Although the MEC theory is more commonly used in marketing research, it has also been used in IS research to study user behavior [20,21]. In these studies, the MEC theory is used to examine how users engage technologies, which possess tangible attributes that can similarly lead to consequences that fulfill their personal 
values. We argue that this perspective can complement the affordance theory to help uncover the motivation behind the goal-oriented action of AR use, by not only identifying what are the tangible attributes that are salient to users, but also why they are salient.

Further, the laddering technique commonly used in MEC studies to elicit attributes of a product that are relevant to consumers' values can be applied as a method to identify properties of the AR artefact that users interact with to produce AR affordances. We view the material properties of IT artefact in the technology affordance framework as synonymous to the tangible attributes construct of the MEC. In sum, by extending the affordance framework with the MEC approach, we can further investigate the motivation (personal values) behind the user's goal-oriented behavior to act on its affordances, that can lead to the actualization of affordances (see Figure 2).

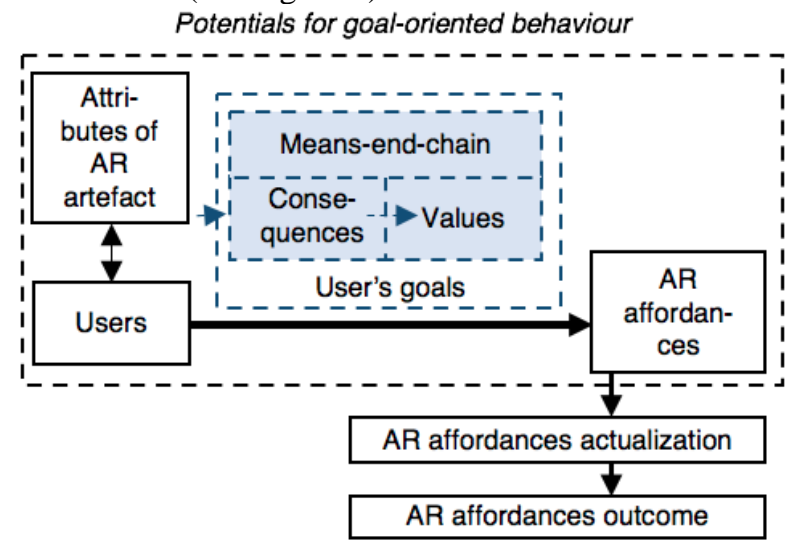

Figure 2. Integrated conceptual framework (synthesized from Pozzi et al. [15] and Gutman [11])

\section{Laddering method}

The laddering method consists of in-depth, one-onone interviews with the goal of developing an understanding of how consumers translate tangible, observable attributes of products into meaningful linkages that relate to the self [10]. The laddering technique coherently follows the logic of MEC, allowing researchers to probe beyond respondents' surface knowledge about the perceived products' attributes and benefits, and to uncover how these are connected to the implicit personal values and beliefs that drive behavior. Instead of product attributes, this study adapts the laddering method to identify the attributes of $\mathrm{AR}$ and the personal values these fulfil. The laddering method employed for this study comprises of three main parts: (1) elicitation of AR attributes that are salient to the respondents; (2) in-depth laddering interviews; and (3) analysis of the results to generate a hierarchical value map (HVM) that visually depicts the attributesconsequences-values linkages.

\subsection{Sample selection}

We recruited 15 participants using purposive, snowball sampling. We started by identifying and subsequently interviewing two $\mathrm{PhD}$ students from a university in China, who were deemed to be sufficiently acquainted with AR technology as they both had direct experience with AR applications. Following the interviews, they provided us with referrals who were identified to have basic knowledge of AR. All 15 participants confirmed that they understood the basic features of AR as defined by Azuma [8]. As it is the research objective of this study to identify what AR can afford users and the personal values that AR attributes can help satisfy, it is important that we collect data from participants who possess the knowledge or experience that can help us in our investigation. Additionally, to avoid gender biases, we ensured that we had an appropriate mix of male and female participants. 6 of our participants were male and 9 were female.

Prior studies that have used the laddering method employed varying sample sizes, ranging from 7 [22], 20 [23], to 1000 respondents [24]. MEC studies with large sample sizes typically employ the 'hard' laddering approach whereby data is collected using questionnaires instead of in-depth interviews. However, the hard laddering approach has been critiqued for its lack of flexibility and consideration for respondents who may find it challenging to recall abstract values on their own without the probing of an interviewer [25]. Additionally, the time required to complete a laddering interview beginning with the elicitation of attributes to final laddering usually takes about 60 to 75 minutes [10]. The average duration of the interviews for this study was 57 minutes. Considering the depth of our interviews that enabled us to uncover our respondents' abstract motivations, and the exploratory nature of our study, we deemed 15 participants as an appropriate sample size.

\subsection{Data collection: Elicitation of AR attributes and obtaining ladders}

Figure 3 illustrates the data collection procedure conducted for this study. The first phase of attribute elicitation provides the base for deeper inquiry into participants' higher level values [26]. To elicit AR attributes from our participants, we asked them to watch 10 videos of different $\mathrm{AR}$ applications used in offline stores and shopping malls (see Table 1). These 10 videos were selected from a search result on YouTube using the keywords "augmented reality in retail". To 
ensure that we have a representative list of diverse AR applications in order to elicit a variety of attributes, while also maintaining parsimony to avoid overloading our participants with too many videos, we selected the videos carefully. We grouped together the AR videos that shared similar functions and uses. When there was an AR app that did not share any similarities with the ones in the groups formed, we created a new group. This grouping process was a reiterative one, which ended after saturation was achieved, and no new groups appeared. We then chose one video from each of the 10 groups formed in this process.

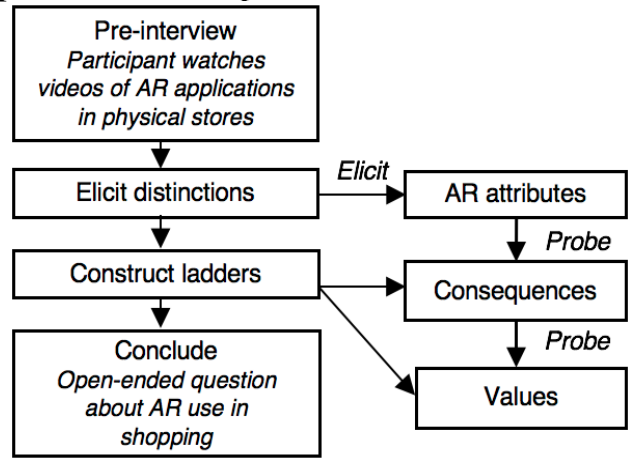

Figure 3. Data collection procedure

Table 1. AR application in offline retail videos

\begin{tabular}{|c|c|}
\hline AR application & Brief description \\
\hline $\begin{array}{l}\text { Supermarket } \\
\text { shopping AR } \\
\text { (Acquia Labs) } \\
\end{array}$ & $\begin{array}{l}\text { Features of AR app include: in-store } \\
\text { navigations, customer ratings, nutritional } \\
\text { information and personalized recommendations. }\end{array}$ \\
\hline $\begin{array}{l}\text { AR product } \\
\text { packaging (SIG-W- } \\
\text { in-a-Box) }\end{array}$ & $\begin{array}{l}\text { Interactive content on packaging allowing users } \\
\text { to tap on information to view narratives of } \\
\text { water's health benefits. }\end{array}$ \\
\hline $\begin{array}{l}\text { AR product } \\
\text { packaging } \\
\text { (Shazam-Bombay } \\
\text { Sapphire) }\end{array}$ & $\begin{array}{l}\text { Users can scan the label on the beverage to } \\
\text { watch animated content. Content includes three } \\
\text { different videos showcasing different recipes. }\end{array}$ \\
\hline $\begin{array}{l}\text { AR in apparel store } \\
\text { (American } \\
\text { Apparel) }\end{array}$ & $\begin{array}{l}\text { AR app features include: showing customer } \\
\text { reviews of products, slideshow of pictures of } \\
\text { modelled clothing, video of modelled clothing, } \\
\text { sharing function and colour assortment of } \\
\text { product. }\end{array}$ \\
\hline $\begin{array}{l}\text { Supermarket } \\
\text { shopping AR } \\
\text { (Hansel) }\end{array}$ & $\begin{array}{l}\text { AR app features include: in-store navigation, } \\
\text { product discount information and personalized } \\
\text { recommendations. }\end{array}$ \\
\hline $\begin{array}{l}\text { AR magic mirror in } \\
\text { apparel store } \\
\text { (UNIQLO) }\end{array}$ & $\begin{array}{l}\text { Magic mirror displaying virtual clothing of } \\
\text { different colour selections onto customer's } \\
\text { camera view. Contains sharing function. }\end{array}$ \\
\hline LEGO store AR & $\begin{array}{l}\text { Displays a 3D animated version of LEGO kit } \\
\text { when customers hold up boxed products in front } \\
\text { of a display screen. }\end{array}$ \\
\hline $\begin{array}{l}\text { AR guidebot in } \\
\text { furniture store }\end{array}$ & $\begin{array}{l}\text { Voice recognition AI chatbot that guides } \\
\text { customers with AR navigation. Also provides } \\
\text { seller recommendation. }\end{array}$ \\
\hline $\begin{array}{l}\text { Treasure hunt AR } \\
\text { in shopping mall }\end{array}$ & $\begin{array}{l}\text { Gamified AR that involves a virtual bird } \\
\text { navigating users around the mall to "unlock" } \\
\text { discounts provided by stores in the mall. }\end{array}$ \\
\hline $\begin{array}{l}\text { AR store window } \\
\text { (VyuAR) }\end{array}$ & $\begin{array}{l}\text { Displays camera view of the store interior that } \\
\text { creates a "transparent screen" effect, allowing } \\
\text { both passer-bys and in-store customers to view } \\
\text { virtual content such as 3D dragons and } \\
\text { promotional information. }\end{array}$ \\
\hline
\end{tabular}

Participants were told that they will later be asked to rank the AR applications in the selected videos based on their preference and thus were encouraged to take down some notes. Ranking is an attribute elicitation technique commonly used in laddering studies [26]. When the ranking was completed, we asked why the participant ranked the AR applications the way they did specifically why he or she preferred one AR application over another. The participant would then compare the AR applications to provide reasons, and from his or her response, the attributes that are used to distinguish the different AR applications are elicited. For instance, when Participant 14 (P14) justified why she ranked one AR application higher over another, she said: "In the first video, the app tells the customer about what's in the product and whether or not it's a [customer] favorite, and the price. This one just tells the customer the price." From this, the provision of rich product information is considered to be an attribute that differentiated the AR application in question over another. We then repeated the same question to address the other AR applications in the participant's ranking list, and continued until the participants no longer named new attributes that led them to rank one application higher or lower than another.

This elicitation process resulted in a list of concrete attributes, which we treat as analogous to the properties of the AR artefact in the affordance framework. We then proceeded with constructing the ladders that link the elicited attributes to their consequences, and consequences to their related values. To achieve this, we focus on each attribute that was elicited from a participant's response (e.g. rich product information) to ask a series of probes that takes some form of the question "Why is that important to you?" for interviewees to achieve higher levels of abstraction in their responses. Upon getting the participant's response, the same questioning (i.e. why is that factor important to him or her) will continue until he or she has nothing further to add. Below is an example taken from our interview with P14:

Interviewer: Why is having information on customer's favorite important to you?

P14: If I have to compare with other products, especially if it is something I have not purchased before, having the star value, which is the number of times customers have picked it up, would be helpful.

Interviewer: Why is comparing between products important to you?

P14: If it's something that I've never bought before, I want to make sure I get the best one out of the other products.

Interviewer: And why is making sure you get the best product important to you? 
P14: So I know I didn't waste my time and money on something that I could've spent on a better product.

From this section of the interview, one ladder is constructed to show the linkages between attribute, consequence and value: rich product information (attribute) $\rightarrow$ facilitate product comparison (consequence) $\rightarrow$ choice optimization (consequence) $\rightarrow$ avoid wastefulness (value). As illustrated in the above example, participants are encouraged to think more abstractly in relevance to the self, resulting in linkages that lead to personal values. However, this is merely one ladder achieved from a single attribute elicited (rich product information), and from one participant. Each and every attribute elicited by every participant during the elicitation stage were followed by such probes to create new ladders. After all attributes were followed up, we concluded the interview by asking participants for their final thoughts about the use of AR in offline retail, if they had any. Although this is not commonly included in laddering interviews, the concluding openended question surprisingly generated some rich insights that would not have been obtained if we adhered to just the conventional semi-structured laddering procedure. These are discussed in our findings section.

\section{Data analysis}

\subsection{Content analysis}

The interview audio recordings were transcribed mostly within 24 hours from when the interview took place. Following the content analysis recommendations by Reynolds and Gutman [10], we first classified all responses into the basic three categories: attributes, consequences and values. Then, the content was assigned individual codes, as per the open coding technique commonly used in qualitative analysis [27]. The interview data were reduced into 26 aggregated codes (see Table 2). The left most column in Table 2 shows the attribute (A), consequence $(\mathrm{C})$ and value $(\mathrm{V})$ categories of the codes. The categorization process of responses into the three groups were informed by prior MEC studies in the IS discipline [20]. Some codes in Table 2 were listed on the aggregated level as its subcodes (raw codes) varied little from each other.

\section{Table 2. Data structure}

\begin{tabular}{|l|l|l|}
\hline & \multicolumn{1}{|c|}{ Raw codes (with sample citations) } & \multicolumn{1}{c|}{$\begin{array}{c}\text { Aggregated } \\
\text { codes and } \\
\text { summary }\end{array}$} \\
\hline A & $\begin{array}{l}\text { Application design (4) - Attributes related to the design of } \\
\text { AR applications. } \\
\text { “... it shows a very clear and simple navigation path. Like } \\
\text { for the bird or the robot navigation ones, you might ... end } \\
\text { up getting lost." }-P 2\end{array}$ \\
\hline
\end{tabular}

\begin{tabular}{|c|c|c|}
\hline A & \multicolumn{2}{|c|}{$\begin{array}{l}\text { Assortment (9) - Consumers have access to an extended } \\
\text { variety of product options. } \\
\text { "I have more variety, and I can see if the colour I want that } \\
\text { looks good on me exists." - P13 }\end{array}$} \\
\hline A & \multicolumn{2}{|c|}{$\begin{array}{l}\text { Interactivity (20) - Three-dimensionality and animation of } \\
\text { virtual items that facilitate consumer interaction. } \\
\text { “... it has a lot of interactions, like the dragons and } \\
\text { promotional messages. I would feel like touching it. This... } \\
\text { helps me remember the information.”-P10 }\end{array}$} \\
\hline A & \multicolumn{2}{|c|}{$\begin{array}{l}\text { Navigation (9) - Virtual paths provided by AR app for } \\
\text { shopper navigation. One AR app also includes a chatbot that } \\
\text { guides shoppers to specific products. } \\
\text { "It helps me determine the right position of a specific item... } \\
\text { It can guide me in the right way..." - P5 }\end{array}$} \\
\hline A & \multicolumn{2}{|c|}{$\begin{array}{l}\text { Online-offline integration (4) - Integration of digital } \\
\text { online information into offline real-world setting. } \\
\text { "It feels like it's a combination of online and offline } \\
\text { shopping, like it combines some online shopping features } \\
\text { with real life product... you can see others" comments and } \\
\text { also to share with others immediately." - P2 }\end{array}$} \\
\hline \multirow{3}{*}{ A } & $\begin{array}{l}\text { Discount information (6) } \\
\text { "I like it when I get promotional } \\
\text { coupons... I would go to the specific } \\
\text { shop immediately."-P5 }\end{array}$ & \multirow{3}{*}{$\begin{array}{l}\text { Rich information } \\
\text { (21) - Additional } \\
\text { information that } \\
\text { would typically be } \\
\text { unavailable in } \\
\text { regular offline } \\
\text { retail stores, such } \\
\text { as additional } \\
\text { discount } \\
\text { information, } \\
\text { extensive product } \\
\text { information and } \\
\text { customer reviews. }\end{array}$} \\
\hline & $\begin{array}{l}\text { Rich product information (10) } \\
\text { "It provides a lot of rich } \\
\text { information... that you did not know } \\
\text { about the products." }-P 8\end{array}$ & \\
\hline & $\begin{array}{l}\text { Customer reviews (5) } \\
\text { "... with customer reviews, I'm able } \\
\text { to get other people's opinion about } \\
\text { the quality of the product after buying } \\
\text { it." }-P 7\end{array}$ & \\
\hline A & \multicolumn{2}{|c|}{$\begin{array}{l}\text { Sharing function (3) - Sharing feature on the } \mathrm{AR} \\
\text { application. } \\
\text { "I can take a picture and share it with my friends. So I can } \\
\text { ask for their opinions..." - P10 }\end{array}$} \\
\hline A & \multicolumn{2}{|c|}{$\begin{array}{l}\text { Vividness (11) - Three-dimensionality and animation of } \\
\text { virtual items that allows for perceptual fidelity of the "real". } \\
\text { "... it's more convincing than just a picture because pictures } \\
\text { can be edited, but with AR, it just looks more real." - }-P 15\end{array}$} \\
\hline \multirow{3}{*}{$\mathrm{C}$} & $\begin{array}{l}\text { Visualise the potential outcome (3) } \\
\text { "Especially if you have a box with } \\
\text { separate toy parts in it, and you can } \\
\text { actually see what it will look like in } \\
\text { the future when you actually build it." } \\
-P 2\end{array}$ & \multirow{3}{*}{$\begin{array}{l}\text { Ability to } \\
\text { visualise (10) - } \\
\text { The ability for } \\
\text { users to have a } \\
\text { vivid visualisation } \\
\text { of a product that is } \\
\text { in a box, of its } \\
\text { potential use } \\
\text { scenarios, and of } \\
\text { its ownership. }\end{array}$} \\
\hline & $\begin{array}{l}\text { Vivid visualisation (6) } \\
\text { "With just a picture, I don't really } \\
\text { know what the product would look } \\
\text { like. But with this, you can really see } \\
\text { its real size. You see the } 3 D \text { model, } \\
\text { with a } 360 \text { angle view. I will have a } \\
\text { more concrete idea about what the } \\
\text { product looks like." -P12 }\end{array}$ & \\
\hline & $\begin{array}{l}\text { Visualise ownership (1) } \\
\text { "It helps me imagine better of how I } \\
\text { can use it. It gives me a perspective of } \\
\text { what it's like to own it."-P13 }\end{array}$ & \\
\hline $\mathrm{C}$ & $\begin{array}{l}\text { Customer experience (6) } \\
\text { "It's not just for advertising, it's for } \\
\text { the entertainment of the customers. It } \\
\text { makes me feel like the shop cares } \\
\text { about the customers..."-P2 }\end{array}$ & $\begin{array}{l}\text { Improved } \\
\text { customer } \\
\text { experience (9) - } \\
\text { Customers have a } \\
\text { memorable and }\end{array}$ \\
\hline
\end{tabular}




\begin{tabular}{|c|c|c|}
\hline & $\begin{array}{l}\text { Memorable experience (3) } \\
\text { "It's such a fun experience... when } \\
\text { you find something like this, you } \\
\text { remember it. It's different." - P15 }\end{array}$ & $\begin{array}{l}\text { improved } \\
\text { customer } \\
\text { experience in the } \\
\text { retail store }\end{array}$ \\
\hline \multirow{4}{*}{$\mathrm{C}$} & $\begin{array}{l}\text { Choice optimisation (7) } \\
\text { "With all these information, I can } \\
\text { compare, then I know which is the } \\
\text { best one to get." - P11 }\end{array}$ & \multirow{4}{*}{$\begin{array}{l}\text { Product } \\
\text { evaluation (30) - } \\
\text { Customers are } \\
\text { able to make } \\
\text { judgments about } \\
\text { the product in } \\
\text { order to make a } \\
\text { purchase decision. }\end{array}$} \\
\hline & $\begin{array}{l}\text { Perceived product worth (8) } \\
\text { "I can make the decision... whether } \\
\text { this product is worth buying."-P2 }\end{array}$ & \\
\hline & $\begin{array}{l}\text { Perceived product fit (9) } \\
\text { "I can try on all the possible colours } \\
\text { and styles to see which one fits me } \\
\text { best."-P6 }\end{array}$ & \\
\hline & $\begin{array}{l}\text { Product expectations (6) } \\
\text { "It helps me know what I'm getting } \\
\text { myself involved in..." - P13 }\end{array}$ & \\
\hline \multirow[t]{2}{*}{ C } & $\begin{array}{l}\text { Intended product use (3) } \\
\text { "From the information, I'll know the } \\
\text { correct way of using it. It's directly } \\
\text { from the producer of the product. That } \\
\text { way I know how to use it the way I'm } \\
\text { supposed to." - P2 }\end{array}$ & \multirow{2}{*}{$\begin{array}{l}\text { Product } \\
\text { optimization (6) } \\
\text { - Customers can } \\
\text { maximise the } \\
\text { value of product } \\
\text { by knowing how } \\
\text { to utilise it. }\end{array}$} \\
\hline & $\begin{array}{l}\text { Maximising product value (3) } \\
\text { "I want to get the maximum value of } \\
\text { this item..." - P5 }\end{array}$ & \\
\hline C & \multicolumn{2}{|c|}{$\begin{array}{l}\text { Curiosity (8) - Arouses consumers' interest and attracts } \\
\text { their attention. } \\
\text { "It will catch my eye and I will be interested to find out } \\
\text { what's going on." }-P 1\end{array}$} \\
\hline $\mathrm{C}$ & \multicolumn{2}{|c|}{$\begin{array}{l}\text { Self-service (4) - AR app substitutes the need for customer } \\
\text { service staff, allowing customers to shop independently. } \\
\text { "It gives me guidance. I don't have to ask anyone else. I just } \\
\text { can do it by myself." - P9 }\end{array}$} \\
\hline $\mathrm{C}$ & \multicolumn{2}{|c|}{$\begin{array}{l}\text { Efficiency (22) - Ability for consumers to achieve } \\
\text { maximum productivity with minimal time and effort. } \\
\text { "I won't need to make so much effort to guess how it will } \\
\text { turn out in real life, so it also saves my time." - } P 2\end{array}$} \\
\hline $\mathrm{C}$ & \multicolumn{2}{|c|}{$\begin{array}{l}\text { Purchase intention (9) - Consumers' intent to make a } \\
\text { purchase } \\
\text { "Actually that was one of the things that would probably } \\
\text { make me buy it, because I'll be able to see how it looks like } \\
\text { and how you can play with it." - P15 }\end{array}$} \\
\hline $\mathrm{C}$ & \multicolumn{2}{|c|}{$\begin{array}{l}\text { Reduced product uncertainty (4) - Consumers feel more } \\
\text { confident about a product } \\
\text { "It's a sense of security that it's something that you know } \\
\text { you will enjoy and need." - P14 }\end{array}$} \\
\hline $\mathrm{C}$ & \multicolumn{2}{|c|}{$\begin{array}{l}\text { Perceived retailer appeal (4) - Consumers are attracted to } \\
\text { the store or mall. } \\
\text { "I will go into the store to try the AR app. And perhaps I } \\
\text { will look around the store too... why not shop around to see } \\
\text { if there are any shoes I'm interested in." - P10 }\end{array}$} \\
\hline V & \multicolumn{2}{|c|}{$\begin{array}{l}\text { Avoid wastefulness (6) - Consumers avoid wasting } \\
\text { precious money, time and effort. } \\
\text { "If I buy something I will never wear, I will feel like it's a } \\
\text { waste of money." - P3 }\end{array}$} \\
\hline V & \multicolumn{2}{|c|}{$\begin{array}{l}\text { Cost saving (6) - Allows consumers to save money } \\
\text { "By making a good judgment and good choice, I don't have } \\
\text { to buy another product. It saves my money." - P6 }\end{array}$} \\
\hline $\mathrm{V}$ & \multicolumn{2}{|c|}{$\begin{array}{l}\text { Happiness (7) - Feelings of joy and positive mood } \\
\text { "It affects how I feel. If I see something cool and interesting, } \\
\text { it just makes me enjoy my shopping experience and it makes } \\
\text { me feel happy." - PI }\end{array}$} \\
\hline $\mathrm{V}$ & \multicolumn{2}{|c|}{$\begin{array}{l}\text { Maximize individual resources (13)-Consumers can } \\
\text { allocate their resources to other priorities in their lives } \\
\text { "Time saving is important because leaves you time to do } \\
\text { other stuff."-P15 }\end{array}$} \\
\hline
\end{tabular}

\begin{tabular}{|l|l|}
\hline $\mathrm{V}$ & $\begin{array}{l}\text { Time saving (22) - Consumers can save time. } \\
\text { "If this app tells me where to go, it's not as time consuming } \\
\text { as trying to find it myself." - P15 }\end{array}$ \\
\hline $\mathrm{V}$ & $\begin{array}{l}\text { Satisfaction (5) - Consumers feel satisfied. } \\
\text { “... buying the best product would satisfy me." - P5 }\end{array}$ \\
\hline & $\begin{array}{l}\text { Sense of empowerment (3) - Consumers can make } \\
\text { decisions and find out about a product independently. }\end{array}$ \\
$\mathrm{V}$ & $\begin{array}{l}\text { ".. I I don't particularly enjoy interacting with salespeople } \\
\text { in apparel stores ... So if I can do it myself, it's a win for } \\
\text { me."-P14 }\end{array}$ \\
\hline
\end{tabular}

\subsection{Hierarchical value map (HVM)}

All direct linkages between aggregated codes were recorded and counted to construct this study's HVM. The HVM is a visual summary that illustrates the most salient linkages connecting the attributes, consequences and values identified in the data collected (see Figure 4). Linkages and boxes in dashed lines indicate that they were mentioned $\geqslant 3$ times; solid lines indicate $\geqslant 5$ mentions; and bold lines indicate $\geqslant 10$ mentions.

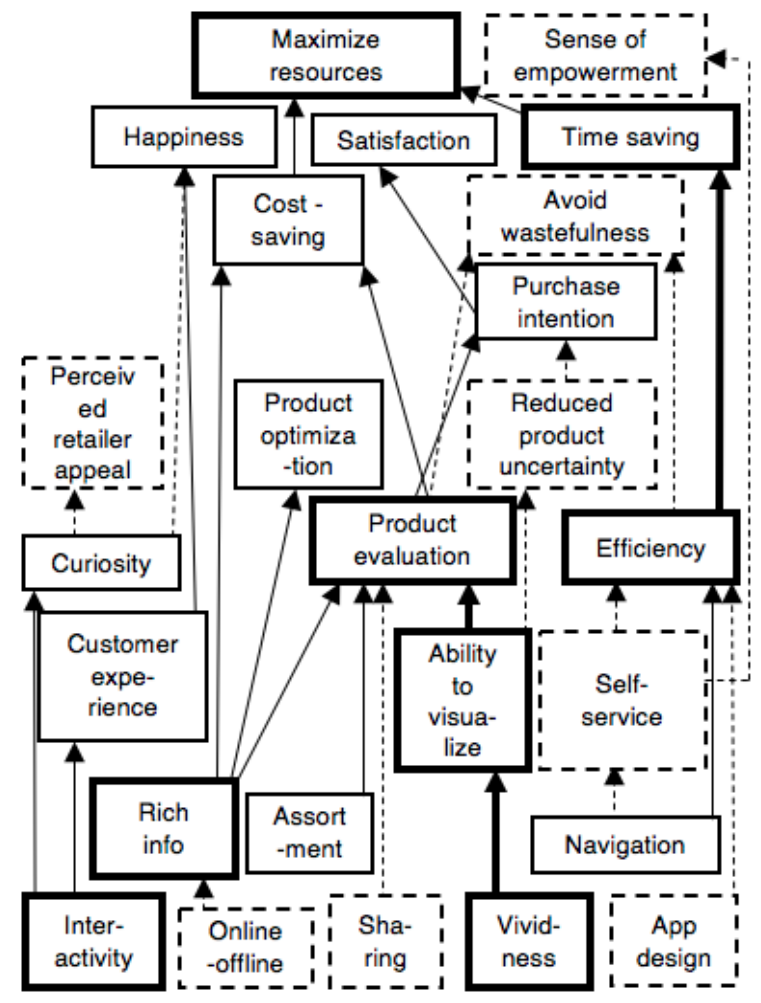

Figure 4. HVM of AR use in offline retail

Although there is no absolute standard for a cut-off level for the construction of HVMs [28], we agreed to set our cut-off point to any linkages less than 3 mentions. Setting a cut-off level is common practice in MEC studies to remove weak relations, and to ensure a parsimonious summary of the strong linkages found [10]. Further, the present HVM accounted for $76 \%$ of all connections mentioned. Thus, the cut-off level is 
considered appropriate. The HVM not only allows us to have a comprehensive overview of our findings, but also to determine the most salient value orientations that motivate the use of AR in offline retail and the cognitive paths that consumers take to gratify their values.

\section{Discussion}

\subsection{Important $A R$ attributes, consequences and user values}

In relation to our first research question, the AR attributes elicited most frequently were AR's vividness, interactivity and the rich information. Prior studies on AR use in e-commerce have also investigated the vividness and interactivity characteristics of AR [5], and this study shows that both attributes are also salient in brick-and-mortar retail stores. However, enriched information appears to be a property of AR that is particularly meaningful in the offline retail context.

We found that when participants were asked to rank and distinguish the AR apps during the attribute elicitation stage, they often mentioned abstract attributes (e.g. rich information) rather than concrete attributes (e.g. integration of virtual information and real environment). This is consistent with the assumption of the MEC theory that consumers focus on the instrumentality of an attribute that are related to their personal values [11]. Therefore, it is unsurprising that participants elicited abstract attributes instead of concrete ones, as the former are directly related to functional consequences and are more closely related to consumers' choices [11, 26]. Conceivably, the link between concrete AR attributes and its consequences is mediated by an abstract attribute [26].

From the abstract attributes, we can infer the concrete attributes of AR. For instance, the threedimensionality of AR gives rise to its vividness property, its real-time interactivity to users' perceived interactivity of the AR apps, and AR's ability to integrate virtual, digital information onto real items and user's surrounding allows for the access of richer information. These are the unique properties of AR that are found to be linked to important benefits or consequences to users, providing insights to our second research question of why shoppers would use AR.

Our findings suggest that the aforementioned attributes of AR can provide functional implications. First, the vividness of product presentations provided by AR apps afford its users the ability to visualize more concretely the potential uses of the product and what it is like to use or own the product. For instance, P15 quoted, "It's like fast forwarding into the future, after you've assembled it and you can see the product in front of your face." This ability in turn aids users in evaluating a product prior to making a purchase decision. For some participants, the ability to visualize the use of a product and ownership of the product also reduces uncertainty towards it, which is also reported to lead to purchase intention.

Second, AR's function of providing digital, online information, such as customer reviews, additional product and discount information that are typically unavailable in brick-and-mortar stores, is found to be directly linked to product evaluation, product optimization and consumer value of cost-saving. On this note, one of our participants, P2 aptly commented, "It feels like it's a combination of online and offline shopping, like it combines some online shopping features with real life products" - providing support to prior literature that has suggested AR's potential in omnichannel retail [7]. The enriched, augmented information allows consumers to make judgments about a product in their purchase decision making process, leading to purchase behavior. Further, the information provided gives users insights on how to maximize the use of the product, in addition to helping users save cost, particularly with information on deals and discounts.

Third, an overall view of the HVM suggests that efficiency is a key benefit of using AR, as pointed out by P14, “... isn't the whole point [of these apps] to make life as simple as possible?". Also, it was found that many of the participants treated shopping as a task, and would prefer it to be completed within the shortest time possible, and with as little cost as possible. When asked why time and cost saving is important, the most cited response was so that they can spend their saved time and money on other items or tasks. For instance, P11 said saving money would mean "we can buy more things for the same budget" and P15 said saving time on shopping tasks would leave her more time for her family and other responsibilities.

Aside from functional consequences, our findings show that the use of AR can also lead to hedonic implications, specifically with AR's real-time interactivity attribute. Although not as frequently mentioned as functional ones, these hedonic implications were cited more than 5 times and are worth discussing. Two of the most mentioned ones were curiosity and positive customer experience. Several participants mentioned that the AR applications used in stores would stimulate their curiosity, especially when they can see other customers engaging with the AR interactively (e.g. like in the AR store window listed in Table 1). To satisfy their curiosity, they would enter the store to experience the AR themselves, which would lead to store exploration - for instance, P10 said, "I will go into the store to try the AR app. And perhaps I will look around the store too because I think yeah, now that 
I' $m$ in the store, why not shop around to see if there are any shoes I'm interested in." Additionally, participants have cited that AR's interactivity attribute also affords an elevated and memorable customer experience, which makes them feel happy. These findings show that AR use in brick-and-mortar stores can help retailers provide customers a differentiated and enjoyable experience, which is something consumers value. As P2 explained, "It makes me feel like the shop cares about the customers and like my experience here matters."

\subsection{AR-related limitations and suggestions}

As mentioned in Section 3.2, the final phase of the data collection involved participants reflecting on the application of AR in offline retail in general. This final step was critical as it allowed participants to openly discuss about some issues related to AR use in offline retail, of which may not have been convenient to mention during the laddering process as the line of questioning pertained to how AR was positively relevant to their personal values. While we did not ask for participants to reflect on AR-related problems specifically, they voluntarily expressed some concerns in relation to AR applications in offline retail.

One recurring issue raised by a total of six participants is the issue of information overload, which is also relevant to another issue mentioned, that is the lack of user control. For instance, P10 explained, "It provides so much information within so little time. Some words are too small for me to read. It pops up and disappears in just a few seconds. It's hard for me to digest the information in such a limited time". P12 also echoed similar thoughts, and suggested, "you can put it [the information] into sub-categories, like if I want to know about a certain aspect of the product, I can just click on it, instead of it giving me really rich product background at once". This would suggest that despite AR's ability to provide rich, augmented information, the same affordance may hinder the effective delivery of such information. However, this issue may be mitigated by presenting information in a palatable manner and giving users control to the information they preferred.

In addition, the next most mentioned problem raised was the range of functions that an AR application can provide and the range of products it can be used for. P14, for instance, expressed her doubts saying that the application "seems very product-specific, which I usually have a pet peeve about, because why would I want to download an app just for it to work on one product in just one store?" However, P6 alluded to a possible solution to this issue in saying "I prefer a combination app. A combination of everything. Because then, you don't need to open different apps for different functions and for different items".
Further, several participants raised their concerns about the feasibility of some AR apps that relied on a single display provided by the retailer, such as virtual try-on mirror types of applications. One participant suggested that compared to using their mobile phones, such applications would be less convenient especially when the store is crowded and customers may have to queue in order to use the mirror, causing the AR application to be counterproductive. Another inconvenience related to hardware that was mentioned by participants is the problem of having to hold a mobile device when using the AR navigation function. Some participants said that it would be difficult to navigate as they would have to hold their handheld devices while pushing a shopping cart, and several participants also mentioned that there might be the danger of bumping into other shoppers as they would be directing all their attention on their phone to navigate.

In sum, we can infer that there are limitations in both the capacities of users and of the AR artefact that may hinder the potential uses of AR. However, some of our participants' suggestions such as effective information presentation and mobility of AR devices may alleviate some of these issues.

\subsection{Interpreting $A R$ affordances}

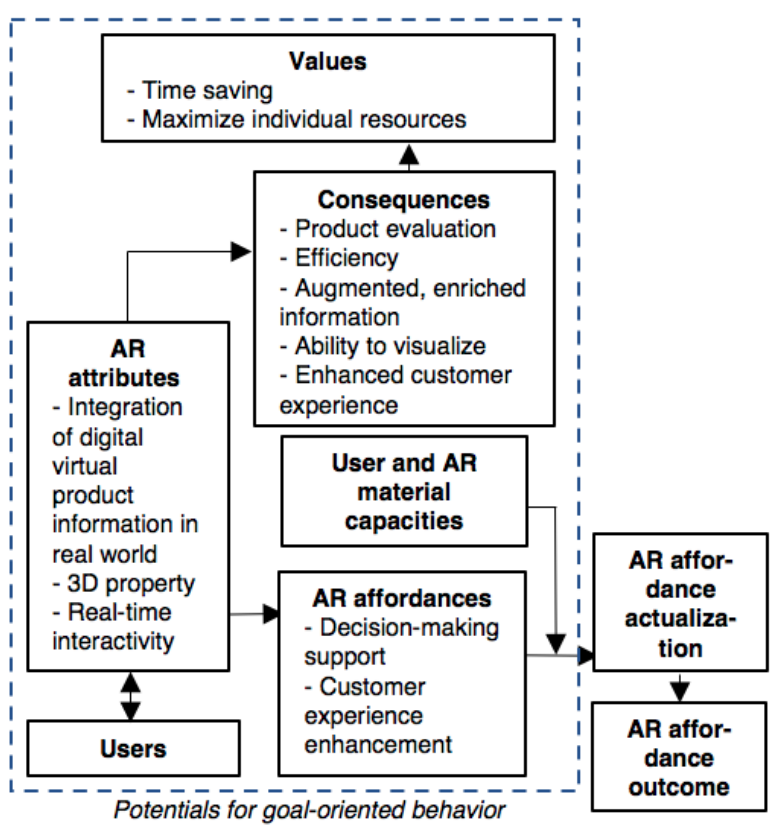

\section{Figure 5. Proposed integrated AR affordance and MEC framework}

Based on our MEC findings, we can summarize and infer the key affordances of AR. We propose that AR affords consumers decision-making support and 
retailers a way to provide consumers an improved customer experience. However, we argue that the actualization of these AR affordances may be constrained by limitations of its material capacities and that of its users, acting as boundary conditions to the actualization of the aforementioned affordances. These relationships are summarized in our proposed framework as illustrated in Figure 5.

The current study has identified the affordance of AR in offline retail as opportunities for consumers' goal-directed behavior to gratify personal values. As this study is largely exploratory, future studies may extend our findings to test the relationships proposed, consistent with prior calls for research attention to investigate the outcomes that occur during IT affordance actualization processes [18]. Thus, it would be worth conducting a field study or experiment to observe and examine the actualization of the proposed AR affordances, and whether these produce desired outcomes in offline retail.

\section{Conclusion}

This study has a limitation, in that our sample selection was largely purposive to achieve our research objective of exploring potential affordances of AR in offline retail and the personal values these can gratify, our findings did not account for possible variations that may have arisen from factors such as user age groups and different levels of technology familiarity. We thus caution against the generalizability of our findings to diverse user populations. While we acknowledge this limitation, we maintain that our selected sample reflects the expected population AR users, who are likely to be digital natives or early adopters of innovative technologies.

The contributions of our study are as follow. Firstly, we demonstrated how the combination of the affordance and MEC perspectives can be useful to capture how users interact with material properties of AR to obtain the consequences that these provide, which ultimately gratify individual personal values. From these linkages, we were able to interpret the affordances of AR, which are considered to be potentials for goal-directed actions. Further, we identified user and AR material capacities as potential boundary conditions, giving support to the key premise of the affordance theory, which asserts that affordances are products of the interaction of both material properties of the artefact and the actor. Thus, it is conceivable that limitations stemming from both elements would also affect the actualization of affordances.

Secondly, as mentioned in Section 2 of this paper, we adopted the affordance theory (which we then extended using the MEC perspective) as an overarching framework to identify the AR use mechanisms that can subsequently be used to build AR-related theories. One possible future research direction is to examine the actualization process of the identified AR affordances. For instance, researchers can test if the attributes of AR does indeed lead to the outcomes proposed in this study. Another potentially fruitful line of research inquiry would be to investigate how information presented by AR may lead to different user responses, and if this would affect the actualization of AR affordances - for example, under what conditions does the enriched information provided by AR afford users decisionmaking support, and under what conditions does this backfire? This is a relevant question to investigate as this study has found that the issue of information overload is a pertinent one. Also, future IS researchers may consider examining if the AR affordance outcomes post-actualization is congruent to the personal values that are found to be related to AR attributes in this study, and if incongruency between the affordance outcomes and expected gratified values from using AR causes undesirable consequences. Thus, future researchers may find our proposed integrated framework useful as an overarching lens to explore new IT artefacts, and generate mechanisms that can be further investigated.

Thirdly, our examination of both the material attributes of AR and how it relates to user values provides both AR developers and retailers with rich insights. Specifically, developers can exploit the relevant $A R$ attributes to design $A R$ applications in a way that makes them personally relevant to users. Our findings also provide retailers with insights on how AR applications can be used in stores to achieve potentially positive outcomes such as enhancement of customer experience and increased purchase intention.

\section{References}

[1] Statista. (2018). Augmented Reality (AR) market size worldwide in 2017, 2018 and 2025. Retrieved from https://www.statista.com/statistics/897587/world-augmentedreality-market-value/

[2] McKone, D., R. Haslehurst and M. Steingoltz. (2016). "Virtual and augmented reality will reshape retail." Retrieved 30 November, 2019, from https://hbr.org/2016/09/virtual-andaugmented-reality-will-reshape-retail.

[3] inVerita. (2019). "5 Applications of Augmented Reality in the Retail Industry." Retrieved May 19, 2020, from https://medium.com/@inverita/5-applications-of-augmentedreality-in-the-retail-industry-4ae3e 774e2c3.

[4] Rese, A., D. Baier, A. Geyer-Schulz and S. Schreiber (2017). "How augmented reality apps are accepted by 
consumers: A comparative analysis using scales and opinions." Technological Forecasting and Social Change 124: 306-319.

[5] Yim, M. Y.-C., S.-C. Chu and P. L. Sauer (2017). "Is augmented reality technology an effective tool for ecommerce? An interactivity and vividness perspective." Journal of Interactive Marketing 39: 89-103.

[6] Hilken, T., K. de Ruyter, M. Chylinski, D. Mahr and D. I. Keeling (2017). "Augmenting the eye of the beholder: exploring the strategic potential of augmented reality to enhance online service experiences." Journal of the Academy of Marketing Science 45(6): 884-905.

[7] Hilken, T. (2018). "Making omnichannel an augmented reality: the current and future state of the art." Journal of Research in Interactive Marketing 12(4): 509-523.

[8] Azuma, R. T. (1997). "A survey of augmented reality." Presence: Teleoperators and Virtual Environments 6(4): 355385 .

[9] Gibson, J. (1986). The Ecological Approach to Visual Perception. Hillsdale, New Jersey, Lawrence Erlbaum Associates.

[10] Reynolds, T. J. and J. Gutman (1988). "Laddering theory, method, analysis, and interpretation." Journal of Advertising Research 28(1): 11-31.

[11] Gutman, J. (1982). "A means-end chain model based on consumer categorization processes." Journal of Marketing 46(2): 60-72.

[12] Volkoff, O. and D. Strong (2017). Affordance theory and how to use it in IS research. The Routledge Companion to Management Information Systems, Routledge.

[13] Leonardi, P. M. (2011). "When flexible routines meet flexible technologies: affordance, constraint, and the imbrication of human and material agencies." MIS Quarterly 35(1): 147-167.

[14] Grgecic, D., R. Holten and C. Rosenkranz (2015). "The impact of functional affordances and symbolic expressions on the formation of beliefs." Journal of the Association for Information Systems 16(7): 580-607.

[15] Pozzi, G., F. Pigni and C. Vitari (2014). Affordance theory in the IS discipline: A review and synthesis of the literature. Twentieth Americas Conference on Information Systems, Savannah.

[16] Wang, H., J. Wang and Q. Tang (2018). "A review of application of affordance theory in information systems " Journal of Service Science and Management 11(1).
[17] Bygstad, B., B. E. Munkvold and O. Volkoff (2016). "Identifying generative mechanisms through affordances: A framework for critical realist data analysis." Journal of Information Technology 31(1): 83-96.

[18] Olson, J. C. and T. Reynolds (1983). Understanding Consumers' Cognitive Structures: Implications for Advertising Strategy. Advertising and Consumer Psychology. L. Percy and A. G. Woodside. Lexington, MA, Lexington Books: 77-90.

[19] Pieters, R., H. Baumgartner and D. Allen (1995). "A means-end chain approach to consumer goal structures." International Journal of Research in Marketing 12(3): 227-244.

[20] Lin, X., Guo, Z., \& D’Ambra, J. (2017). Analyzing consumer goal structure in online group buying. Information and Management, 54(8), 1097-1119. doi:10.1016/j.im.2017.03.001

[21] Chiu, C.-M. (2005). "Applying means-end chain theory to eliciting system requirements and understanding users perceptual orientations." Information \& Management 42(3): 455-468.

[22] Yang, X. and S. Gao (2017). Understanding the values of live game streaming: a value-focused thinking approach. The Sixteenth Wuhan International Conference on E-Business.

[23] Bianchi, C., V. Reyes and V. Devenin (2020). "Consumer motivations to purchase from benefit corporations (B Corps)." Corporate Social Responsibility and Environmental Management.

[24] Brunsø, K., J. Scholderer and K. G. Grunert (2004). "Closing the gap between values and behavior - a means-end theory of lifestyle." Journal of Business Research 57(6): 665670.

[25] Phillips, J. and T. Reynolds (2009). "A hard look at hard laddering: A comparison of studies examining the hierarchical structure of means-end theory." Qualitative Market Research: An International Journal 12: 83-99.

[26] Bech-Larsen, T. and N. A. Nielsen (1999). "A comparison of five elicitation techniques for elicitation of attributes of low involvement products." Journal of Economic Psychology 20(3): 315-341.

[27] Corbin, J., \& Strauss, A. (2008). Basics of Qualitative Research: Techniques and Procedures for Developing Grounded Theory (3rd ed.). Thousand Oaks, California.

[28] Grunert, K. G. and S. C. Grunert (1995). "Measuring subjective meaning structures by the laddering method: Theoretical considerations and methodological problems." International Journal of Research in Marketing 12(3): 209-225. 